\title{
ATIVIDADE DE DETERRÊNCIA ALIMENTAR DO ÓLEO ESSENCIAL DE LARANJA AMARGA SOBRE Helicoverpa armigera HÜBNER
}

\author{
Victor Luiz de Souza Lima ${ }^{1}$ \\ Cristhian Eliseo Durán Aguirre ${ }^{2}$ \\ João Marcos Caliman Colodette ${ }^{3}$ \\ Saulo Pedroti Spala Oliveira ${ }^{4}$ \\ Dirceu Pratissoli ${ }^{5}$
}

\begin{abstract}
Resumo: Diversas plantas possuem compostos secundários com propriedades inseticidas e o óleo essencial de laranja amarga mostra-se com grande potencial para o controle de pragas. Recentemente, foi registrada no Brasil a espécie Helicoverpa armigera, uma das maiores pragas da agricultura mundial. Tendo em vista a falta de métodos alternativos aos inseticidas para o controle dessa praga, o objetivo desse trabalho foi avaliar os efeitos do óleo essencial de laranja amarga sobre $\mathrm{H}$. armigera. Foi realizado um teste de escolha para avaliar a atividade deterrente. Folhas de tomate foram imersas em soluções contendo óleo de laranja amarga em três concentrações (1, 10 e $\left.100 \mathrm{mg} \mathrm{L}^{-1}\right)$. As folhas tratadas com óleo e folhas não tratadas foram oferecidas à lagartas de segunda instar e após $24 \mathrm{~h}$ foi calculado o índice de deterrência alimentar (IDA). A concentração de $1 \mathrm{mg} \mathrm{L^{-1 }}$ apresentou $71 \%$ de deterrência alimentar. Porém as concentrações de 10 e $100 \mathrm{mg} \mathrm{L}^{-1}$ causaram fitotoxidez às folhas de tomate, inviabilizando o consumo pelas lagartas e a estimativa do IDA. Novos testes devem ser realizados com concentrações menores para evitar a fitotoxidez.

Palavras-chave: Deterrência alimentar; Óleo essencial; Citrus; Fitotoxicidade; Noctuidae.
\end{abstract}

\footnotetext{
${ }^{1}$ Pós-Doutorado/CCAE-UFES, Brasil. Email: victor.souzalima@gmail.com.

2 Mestrado em Produção Vegetal/CCAE-UFES, Brasil. E-mail: cduran_21@hotmail.com.

3 Agronomia/CCAE-UFES, Brasil. E-mail: joaocolodette@gmail.com.

${ }^{4}$ Agronomia/CCAE-UFES, Brasil. E-mail: saulospala@gmail.com.

${ }^{5}$ Professor do curso de Agronomia/CCAE-UFES, Brasil. E-mail: dirceu.pratissoli@gmail.com.
} 